Research Paper

\title{
Gene expression and single nucleotide polymorphism of ATP7B are associated with platinum-based chemotherapy response in non-small cell lung cancer patients
}

\author{
Yue-Qin Li1,2, Juan Chen ${ }^{1,2}$, Ji-Ye Yin², Zhao-Qian Liu², Xiang-Ping Li1 ${ }^{1,2},{ }^{凶}$ \\ 1. Department of Pharmacy, Xiangya Hospital, Central South University, Changsha, P.R. China \\ 2. Department of Clinical Pharmacology, Xiangya Hospital, Central South University, Institute of Clinical Pharmacology, Central South University, Hunan \\ Key Laboratory of Pharmacogenetics, Changsha, P.R. China. \\ $\triangle$ Corresponding author: Professor Xiang-Ping Li. Address: 87 Xiangya Road, Changsha, Hunan Province, P. R. China, 410008 . Tel: +86 731 84327453, Fax: +86 \\ 731 84327453. Email: xylxping@csu.edu.cn. \\ (C) Ivyspring International Publisher. This is an open access article distributed under the terms of the Creative Commons Attribution (CC BY-NC) license \\ (https://creativecommons.org/licenses/by-nc/4.0/). See http://ivyspring.com/terms for full terms and conditions.
}

Received: 2018.03.25; Accepted: 2018.07.26; Published: 2018.09.08

\begin{abstract}
Objectives: Platinum-based chemotherapy is first-line treatment for non-small cell lung cancer (NSCLC) patients. The efficacy is limited by drug resistance. Recent studies suggest that ATP7B, a copper efflux transporter, may be involved in platinum resistance. However, the clinical significance of ATP7B expression in NSCLC is controversial. Moreover, the effects of single nucleotide polymorphisms (SNPs) in ATP7B gene on the response to platinum-based chemotherapy are scarcely understood. The aim of our study is to evaluate the clinical value of ATP7B in NSCLC patients and explore the interrelationships between ATP7B SNPs and protein expression, and their association with chemotherapy response.

Materials and Methods: A total of 247 NSCLC patients were recruited in this study. Among them, 158 patients who received platinum-based chemotherapy were used to explore the interrelationships between ATP7B SNPs, protein expression and chemotherapy response, while 89 patients who underwent surgical resection were used to further investigate the association between ATP7B SNPs and expression level. We genotyped 15 SNPs of ATP7B by Sequenom MassARRAY and determined ATP7B protein levels by immunohistochemistry.

Results: Patients with ATP7B-negative tumors had improved chemotherapeutic response $(p=0.025)$ and better overall survival $(p=0.044)$ compared with the patients with ATP7B-positive tumors. The multivariate Cox regression analysis revealed that ATP7B expression was an independent prognostic factor $(H R=0.639$, $95 \% \mathrm{Cl}=0.424-0.962, p=0.032$ ). Moreover, we found that the rs9526814 GG genotype was significantly associated with favorable response to platinum-based chemotherapy when compared with TT+TG genotypes $(O R=0.362,95 \mathrm{Cl} \%=0.140-0.935, p=0.036)$. Mechanistically, rs9526814 GG genotype showed a strong trend towards reduced expression level of ATP7B compared with the TT+TG genotypes $(p=0.048)$.

Conclusion: Our findings indicate that $A T P 7 B$ rs 9526814 may contribute to platinum resistance by influencing ATP7B gene expression and can be used as a potential biomarker to predict the sensitivity of platinum-based chemotherapy in NSCLC patients.
\end{abstract}

Key words: NSCLC, platinum resistance, ATP7B, treatment outcome, SNP

\section{Introduction}

Non-small cell lung cancer (NSCLC), the most common type of lung cancer, has been one of the leading causes for cancer-related death worldwide [1]. Platinum-based chemotherapy is the standard first-line therapy for NSCLC patients. However, the overall response rate is only $25-30 \%[2,3]$. Drug resistance is a major obstacle to obtain successful treatment. Molecularly, multiple mechanisms have been proposed for platinum resistance [4]. One mechanism of resistance is reduced intracellular 
accumulation of platinum drug owing to the impairment of drug transport in tumor cells.

Recent studies have revealed that copper and platinum drug may share the same transporter system [5]. Copper transporters not only maintain copper homeostasis, but also are involved in the transport of platinum drug and ultimately contribute to platinum resistance [6-8]. ATP7B, a copper efflux transporter, has been demonstrated to deliver platinum drug out of cells. Over-expression of ATP7B has been observed in multiple cancers. Moreover, the expression of ATP7B is associated with the response to platinum-based chemotherapy in patients with ovarian cancer or several other cancers [9-14]. Currently, only a limited number of studies have focused on the role of ATP7B in platinum resistance in NSCLC patients, resulting in highly conflicting results [15-17]. This indicates the need for further studies to clarify the clinical significance of ATP7B in NSCLC patients. On the other hand, most studies have focused on protein expression, and the value of $A T P 7 B$ gene polymorphisms has not been fully addressed. It has been shown that single nucleotide polymorphisms (SNPs) might affect gene expression and function, accounting for interindividual differences in drug efficacy and toxicity $[18,19]$. A few $A T P 7 B$ SNPs have been reported possible role in chemotherapeutic toxicity [20,21]. However, less is known about the effects of SNPs on the expression level of ATP7B and the response to platinum-based chemotherapy in NSCLC patients.

In the present study, we evaluated the expression of ATP7B in NSCLC tissues and genotyped 15 SNPs of ATP7B in 247 NSCLC patients. Moreover, the interrelationships between $A T P 7 B$ SNPs and protein expression, and their association with chemotherapy response were explored.

\section{Materials and Methods}

\section{Patients}

The 247 NSCLC patients enrolled in the study consisted of two sets: (1) 158 patients who received platinum-based chemotherapy were used to explore the interrelationships between $A T P 7 B$ SNPs and protein expression, and their association with chemotherapy response; and (2) 89 patients who underwent surgical resection of the tumor lesions were used to further investigate the association between $A T P 7 B$ SNPs and expression level. All patients were recruited from Xiangya Hospital, Central South University (Changsha, China) between December 2010 and December 2016.

Peripheral blood and tumor tissue were obtained from 158 NSCLC patients receiving platinum-based chemotherapy. The tumor tissues were collected via biopsy of bronchofiberscope and paraffin-embedded in the Pathology Department of Xiangya Hospital. The tumor tissues were required for evaluation of ATP7B expression by immunohistochemistry, while peripheral blood samples for extracting DNA. The details of criteria for patient recruitment and chemotherapy regimens were described elsewhere [22]. Briefly, those 158 cases met the following criteria: (1) All patients were histologically or cytologically diagnosed with primary NSCLC; (2) They were not given surgical or radiation treatment and/or biological therapy before and during chemotherapy; (3) They were treated with at least two cycles of platinum-based chemotherapy including cisplatin/ carboplatin + gemcitabine, cisplatin/carboplatin + navelbine, cisplatin/carboplatin + docetaxel, cisplatin/carboplatin + paclitaxel, and cisplatin/ carboplatin + pemetrexed; (4) They received full follow-up after treatment. Those who were having pregnancy, lactation, active infection, symptomatic brain or leptomeningeal metastases, and other previous or concomitant malignancies were excluded from the study.

89 NSCLC tissue samples from tumor resections were also included in the present study, which were paraffin-embedded in the Pathology Department of Xiangya Hospital. The cases were underwent primary surgical resection of the tumor lesions, without receiving any preoperative treatment. The tumor tissues were used for DNA isolation and immunohistochemistry.

This study was approved by Xiangya Medical Ethics Committee, Central South University (No.CTXY-110008-2). The procedures were performed according to the approved guidelines and to the 1964 Helsinki Declaration and its later amendments or comparable ethical standards. Each participant was voluntary and provided signed informed consent.

\section{Clinical evaluation in 158 NSCLC patients receiving platinum-based chemotherapy}

After the first two cycles of treatment, the response of patients to chemotherapy was evaluated according to the Response Evaluation Criteria in Solid Tumor Group guidelines [23]. In the current study, the patients with complete response (CR) or partial response (PR) were considered as drug sensitive, whereas patients with stable disease (SD) or progressive disease (PD) were defined as drug resistance. For survival analysis, the overall survival (OS) time was calculated as the period between the date of pathological diagnosis and the date of death or last follow-up. The follow-up for the patients was updated in March 13, 2018. At that time, 112 patients died of NSCLC and 46 patients were alive. 


\section{Tumor tissue preparation and immunohistochemistry}

All tissue specimens were collected via biopsy of bronchofiberscope or surgical resection. Appropriate regions of tumor judged by Hematoxylin and Eosin staining were selected. Immunohistochemistry was successfully performed on 247 samples. Representative $4 \mu \mathrm{m}$ tissue sections were deparaffinized in xylene and rehydraded in graded ethanol solutions, and then subjected to heat-induced antigen retrieval by microwave treatment in citrate buffer. Subsequently, endogenous peroxidase activity was quenched by incubation in $3 \% \mathrm{H}_{2} \mathrm{O}_{2} /$ methanol solution for $20 \mathrm{~min}$ at room temperature, and nonspecific staining was blocked by 5\% BSA for 60 $\min$ at $37^{\circ} \mathrm{C}$. The sections were then incubated overnight at $4^{\circ} \mathrm{C}$ with rabbit polyclonal antibody against ATP7B (dilution, 1:250; Abcam). On the next day, the sections were washed with PBS three times, and then incubated with a biotin-labeled goat anti-rabbit antibody and peroxidase-conjugated streptavidin (Boster, Wuhan, China). The staining was visualized by using 3,3'-diaminobenzidine tetrahydrochloride. Finally, the sections were counterstained with hematoxylin, dehydrated and mounted. Positive and negative controls were performed in each staining run.

Slides for all samples were independently evaluated by two pathologists using Leica DMI 4000B inverted microscope. The score of staining in each case was evaluated semiquantitatively as previously described [24]. Briefly, the staining was scored by assessing the intensity (on a 0-3 scale: 0 , no staining of tumor cells; 1 , weak; 2 , moderate; 3 , strong staining) and by estimating the percentage of positive tumor cells (on a $0-4$ scale: 0 , less than $5 \% ; 1,5 \%-25 \%$; 2 , $26 \%-50 \% ; 3,51 \%-75 \% ; 4$, more than $75 \%)$. Total score ranging from 0 to 12 was obtained by multiplying the grades of extent and intensity of staining. Scores of $<1$ were considered as negative and scores of $\geq 1$ were considered as positive levels of expression.

\section{DNA isolation from whole-blood and tumor material}

DNA from peripheral blood of 158 patients was isolated using the Genomic DNA Purification Kit (Promega, Madison, WI, USA) following the standard protocols. Moreover, DNA was extracted from 89 paraffin embedded tissue samples using the QIAamp DNA FFPE Tissue Kit (Qiagen, Hilden, Germany), according to the manufacturer's instructions. DNA was extracted from 5-10 FFPE tissue, depending on the size of the tumor region. All of DNA samples were stored at $-20{ }^{\circ} \mathrm{C}$ before use. DNA concentration and quality were measured using the Biospec-nano spectrophotometer (Shimadzu, Kyoto, Japan). Given that the DNA extraction of some samples was unsatisfactory, we excluded 10 samples from 158 patients receiving platinum-based chemotherapy, such that 148 patients were used for genotyping. The DNAs of 89 tumor tissues were successfully extracted.

\section{SNP selection and genotyping}

According to the data from the HapMap, 1000 Genomes, or previous studies, a total of 15 potentially functional SNPs or tag SNPs with minor allele frequency $(\mathrm{MAF}) \geq 0.05$ in the Chinese population were selected. The tag SNP selection was performed using the Tagger program implemented in Haploview version 4.2, and the potential functional SNPs were included in present study according to the following criteria: (1) SNPs in miRNA binding sites of 3'-UTR; (2) SNPs in the 5'-UTR; (3) SNPs in splice sites and exons; (4) SNPs with a previously suggested function. Those SNPs were genotyped by the Sequenom MassARRAY system (Sequenom, San Diego, California, USA). Primers were designed by AssayDesigner 3.1 software (Sequenom, San Diego, California, USA).

\section{Statistical analysis}

The relationship between ATP7B protein expression in tumors and clinicopathological characteristics, and that between SNP genotype and ATP7B level was evaluated using $\chi^{2}$ or Fisher's exact tests. Survival curve for OS was constructed using the Kaplan-Meier method, and log-rank test was carried out to evaluate differences between groups. Multivariate prognostic analysis was performed using Cox proportional hazards model. Unconditional logistical regression analysis was conducted to calculate the adjusted odds ratio (OR) with 95\% confidence intervals $(95 \% \mathrm{CI})$ of the association between $A T P 7 B$ polymorphisms and chemotherapy response with adjustments for age, sex, histological type, clinical stage, and differentiation. For each SNP, three genetic models (dominant, additive and recessive models) were used for analysis. All statistical analyses were performed by PLINK version 1.07 (Cambridge, MA, USA) and SPSS 13.0 (SPSS Inc., Chicago, Illinois, USA). The $p$ value was two-sided and $p<0.05$ was considered statistically significant.

\section{Results}

\section{ATP7B expression and treatment outcome of platinum-based chemotherapy}

To investigate the association between ATP7B expression and chemotherapy response, immunohistochemistry method was employed in 158 NSCLC patients who received platinum-based 
chemotherapy. The clinicopathologic characteristics of the patients were summarized in Table 1 . All of the 158 patients were treated with platinum-based chemotherapy for at least two cycles. ATP7B-positive expression was detected in cytoplasm of tumor cells in 98 of $158 \quad(62.0 \%)$ tumors. Representative immunohistochemistry samples were shown in figure 1. Interestingly, patients with ATP7B-positive tumors had inferior response to chemotherapy (33.7\% complete and partial response, and $66.3 \%$ no response) compared with the patients with ATP7B-negative tumors (51.7\% complete and partial response, and $48.3 \%$ no response) ( $p=0.025)$. However, no significant association was found between ATP7B expression and age, sex, histological type, clinical stage and differentiation.

Table 1. Clinicopathological characteristics with ATP7B protein expression in 158 NSCLC patients treated with platinum-based chemotherapy.

\begin{tabular}{lllll}
\hline Characteristics & All patients & $\begin{array}{l}\text { ATP7B (+) } \\
\mathbf{n}(\%)\end{array}$ & $\begin{array}{l}\text { ATP7B (-) } \\
\mathbf{n}(\%)\end{array}$ & $p$ value \\
\hline $\begin{array}{l}\text { All patients } \\
\text { Age }\end{array}$ & $158(100.0)$ & $98(62.0)$ & $60(38.0)$ & \\
$\begin{array}{l}<0 \text { years } \\
\begin{array}{l}\text { 60years } \\
\text { Gender }\end{array}\end{array}$ & $80(50.6)$ & $51(52.0)$ & $29(48.3)$ & 0.651 \\
Male & $78(49.4)$ & $47(48.0)$ & $31(51.7)$ & \\
\hline
\end{tabular}
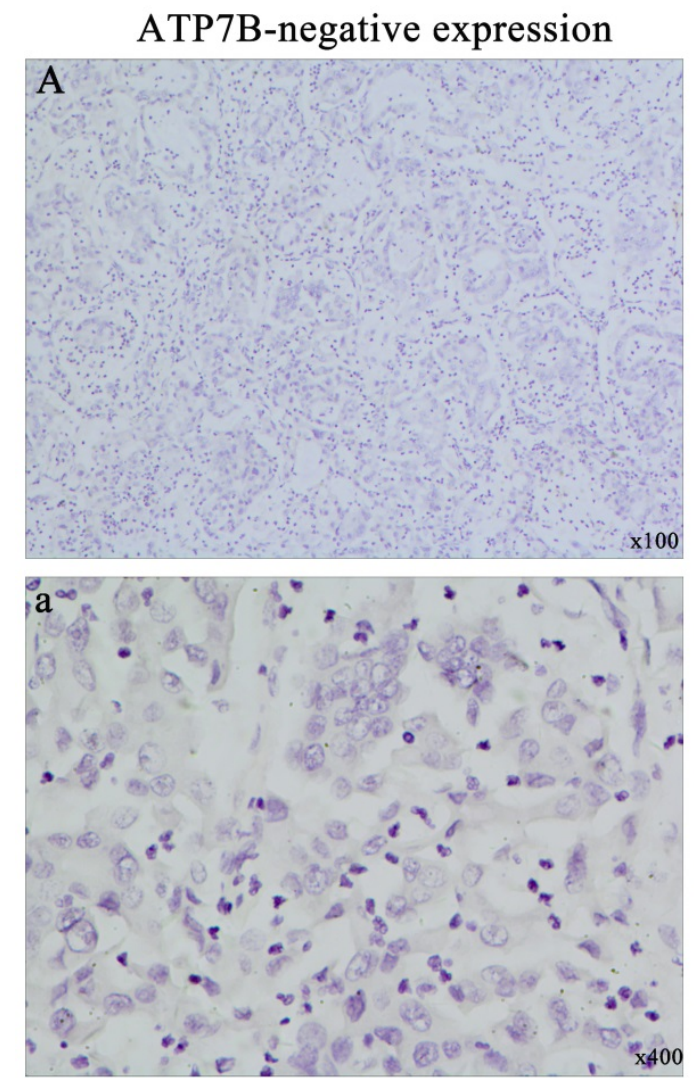

\begin{tabular}{lllll}
\hline Characteristics & All patients & $\begin{array}{l}\text { ATP7B }(+) \\
\mathbf{n}(\%)\end{array}$ & $\begin{array}{l}\text { ATP7B }(-) \\
\mathbf{n}(\%)\end{array}$ & $p$ value \\
\hline $\begin{array}{l}\text { Female } \\
\text { Histology }\end{array}$ & $23(14.6)$ & $18(18.4)$ & $5(8.3)$ & \\
$\begin{array}{l}\text { Adenocarcinoma } \\
\text { Squamous cell carcinoma }\end{array}$ & $60(38.0)$ & $43(43.9)$ & $17(28.3)$ & 0.138 \\
$\begin{array}{l}\text { Adenosquamous } \\
\text { Clinical stage }\end{array}$ & $95(60.0)$ & $53(54.1)$ & $42(70.0)$ & \\
II & & $2(2.0)$ & $1(1.7)$ & \\
III & $6(3.8)$ & $2(2.0)$ & $4(6.7)$ & 0.334 \\
IV & $56(35.4)$ & $35(35.7)$ & $21(35.0)$ & \\
$\begin{array}{l}\text { Differentiation } \\
\text { Poor }\end{array}$ & $96(60.8)$ & $61(62.3)$ & $35(58.34)$ & \\
$\begin{array}{l}\text { Moderate } \\
\text { Well }\end{array}$ & $67(42.4)$ & $43(43.9)$ & $24(40.0)$ & 0.695 \\
Chemotherapy response & $74(46.8)$ & $46(46.9)$ & $28(46.7)$ & \\
Responders & $17(10.8)$ & $9(9.2)$ & $8(13.3)$ & \\
Nonresponders & $64(40.5)$ & $33(33.7)$ & $31(51.7)$ & 0.025 \\
\hline
\end{tabular}

The Kaplan-Meier method was used to assess OS probability for ATP7B expression (Figure 2). The patients with ATP7B-positive carcinomas had poorer overall survival than those with ATP7B-negative tumors $(p=0.044)$. The median overall survival of ATP7B positive and negative carcinomas was 22.4 and 29.4 months, respectively. To further evaluate the independent parameters such as clinicopathologic characteristics, a multivariate Cox proportional hazards regression analysis was performed. Expression statuses of ATP7B, gender, age, histology, clinical stage and differentiation were included as covariates in the Cox proportional hazard model. We

\section{ATP7B-positive expression}
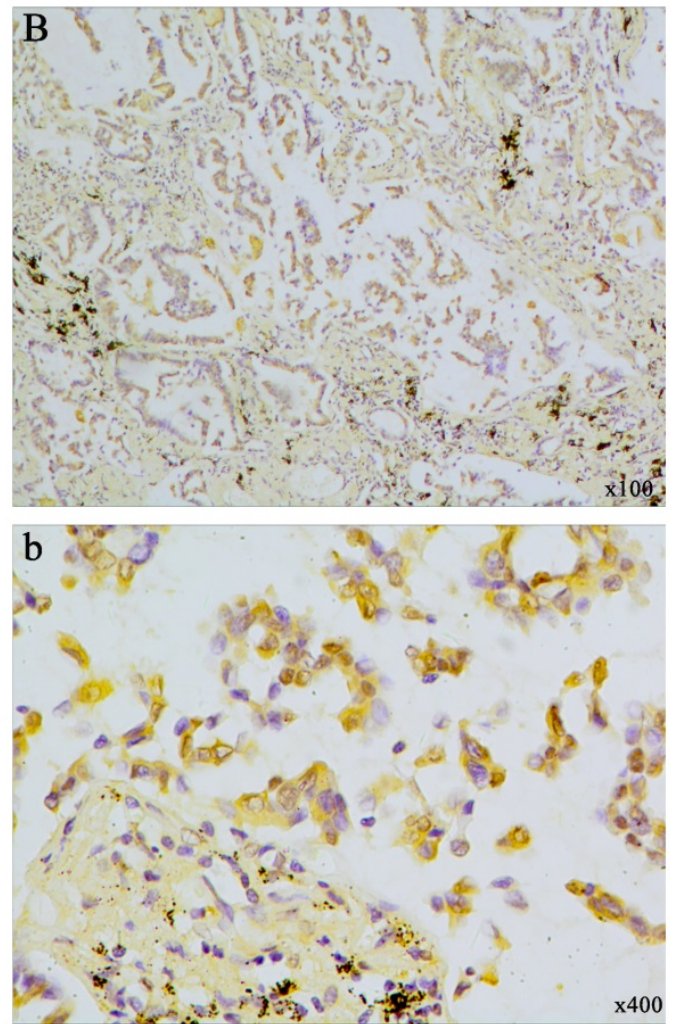

Figure 1. Representative picture of immunohistochemical staining for ATP7B expression in NSCLC tissues. (A) (a): ATP7B negative expression; (B) (b): ATP7B positive expression. Original magnification $\times 100$ for $A$ and $B$, original magnification $\times 400$ for $a$ and $b$. 
found that in the multivariate Cox model, ATP7B expression was the only significant prognostic factor of OS after controlling for gender, age, histology, clinical stage and differentiation $(\mathrm{HR}=0.639$, $95 \% \mathrm{CI}=0.424-0.962, p=0.032$ ) (Table 2). Furthermore, we conducted a stepwise analysis and found that ATP7B expression was the only variable left in the final model. On the basis of above results, ATP7B expression appeared to be a predictor for treatment outcome of platinum-based chemotherapy in NSCLC patients.

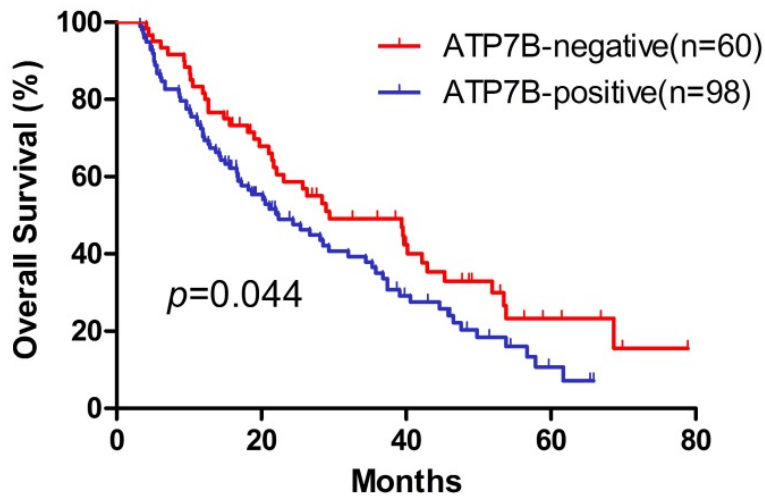

Figure 2. Kaplan-Meier overall survival curves in 158 NSCLC patients treated with platinum-based chemotherapy. ATP7B-negative expression vs. ATP7B-positive expression.

Table 2. Univariate and multivariate analysis for overall survival in 158 NSCLC patients treated with platinum-based chemotherapy.

\begin{tabular}{|c|c|c|c|c|}
\hline \multirow[t]{2}{*}{ Variables } & \multirow{2}{*}{$\begin{array}{l}\text { Univariate analysis } \\
p \text { value }\end{array}$} & \multicolumn{3}{|c|}{ Multivariate Cox analysis } \\
\hline & & HR & CI 95\% & $p$ value \\
\hline \multicolumn{5}{|l|}{ Age } \\
\hline$<60$ years & 0.958 & Reference & & \\
\hline 260years & & 0.931 & $0.630-1.377$ & 0.721 \\
\hline \multicolumn{5}{|l|}{ Gender } \\
\hline Male & 0.994 & Reference & & \\
\hline Female & & 0.932 & $0.533-1.629$ & 0.805 \\
\hline \multicolumn{5}{|l|}{ Histology } \\
\hline Adenocarcinoma & 0.167 & Reference & & \\
\hline $\begin{array}{l}\text { Squamous cell } \\
\text { carcinoma }\end{array}$ & & 1.066 & $0.699-1.624$ & 0.767 \\
\hline Adenosquamous & & 3.051 & $0.894-10.411$ & 0.075 \\
\hline \multicolumn{5}{|l|}{ Clinical stage } \\
\hline II & 0.866 & Reference & & \\
\hline III & & 0.805 & $0.305-2.123$ & 0.661 \\
\hline IV & & 0.929 & $0.363-2.377$ & 0.878 \\
\hline \multicolumn{5}{|l|}{ Differentiation } \\
\hline Poor & 0.856 & Reference & & \\
\hline Moderate & & 0.966 & $0.640-1.456$ & 0.867 \\
\hline Well & & 1.140 & $0.565-2.303$ & 0.714 \\
\hline \multicolumn{5}{|l|}{ ATP7B expression } \\
\hline ATP7B-positive & 0.044 & Reference & & \\
\hline ATP7B-negative & & 0.639 & $0.424-0.962$ & 0.032 \\
\hline
\end{tabular}

HR: hazard ratio; CI: confidence interval.

\section{Association between SNPs and chemotherapy response}

Next, we evaluated the relationship between $A T P 7 B$ SNPs and chemotherapy response in the 158 NSCLC patients receiving platinum-based chemotherapy. DNA was successfully obtained from 148 samples. A total of 15 SNPs were genotyped in present study. As described in Table 3, the call rates of them ranged from 91.2 to $100 \%$ and the MAF of each SNP was $>0.05$. The genotype distributions of the SNPs were in accordance with the Hardy-Weinberg equilibrium (significance threshold $p<0.001$ ).

Table 3. The 15 gene polymorphisms examined in this study.

\begin{tabular}{|c|c|c|c|c|c|c|}
\hline SNP & $\begin{array}{l}\text { Chromosome } \\
\text { Position }\end{array}$ & Region & Alleles $^{a}$ & MAFb $^{\mathbf{b}}$ & $\begin{array}{l}\text { Call Rate } \\
(\%)\end{array}$ & $\begin{array}{l}\text { HWE } p \\
\text { value }\end{array}$ \\
\hline rs9563084 & 13: 52585993 & $\begin{array}{l}\text { Near } \\
\text { 5UTR }\end{array}$ & G:A & 0.486 & 95.9 & 0.012 \\
\hline rs2277448 & 13: 52585548 & 5 UTR & G:T & 0.407 & 94.6 & 0.053 \\
\hline rs73184328 & 13: 52570395 & Intron 1 & A:G & 0.290 & 96.6 & 0.687 \\
\hline rs1801243 & 13: 52548140 & Exon 2 & $\mathrm{~A}: \mathrm{C}$ & 0.461 & 95.3 & 0.091 \\
\hline rs1801244 & 13: 52544805 & Exon 3 & $\mathrm{G}: \mathrm{C}$ & 0.493 & 95.3 & 0.613 \\
\hline rs2147363 & 13: 52542796 & Intron 3 & G:T & 0.489 & 95.3 & 0.736 \\
\hline rs9526814 & 13: 52539526 & Intron 4 & G:T & 0.358 & 100.0 & 0.155 \\
\hline rs1061472 & 13: 52524488 & Exon 10 & C:T & 0.393 & 94.6 & 0.723 \\
\hline rs732774 & 13: 52523808 & Exon 12 & $\mathrm{~T}: \mathrm{C}$ & 0.377 & 98.6 & 0.601 \\
\hline rs1801249 & 13: 52515354 & Exon 16 & G:A & 0.392 & 97.3 & 0.730 \\
\hline rs2282057 & 13: 52511606 & Intron 18 & A:G & 0.407 & 91.2 & 0.477 \\
\hline rs1051332 & 13: 52507720 & 3UTR & $\mathrm{T}: \mathrm{C}$ & 0.323 & 97.3 & 0.849 \\
\hline rs928169 & 13: 52507110 & 3UTR & $C: G$ & 0.388 & 93.9 & 0.592 \\
\hline rs9535793 & 13: 52506762 & $\begin{array}{l}\text { Near } \\
\text { 3UTR }\end{array}$ & G:A & 0.403 & 97.3 & 0.730 \\
\hline rs2031992 & 13: 52506372 & $\begin{array}{l}\text { Near } \\
\text { 3UTR }\end{array}$ & C:T & 0.330 & 99.3 & 0.852 \\
\hline
\end{tabular}

a Minor : major

$\mathrm{b} \mathrm{MAF}=$ minor allele frequency

c Numbers may not add up to $100 \%$ of available subjects because of missing genotyping data.

As shown in Table 4, after adjustment for age, sex, clinical stage, histological type and differentiation, we found that rs9526814 was significantly associated with the efficacy of platinum-based chemotherapy in the recessive model. Compared with TT+TG genotypes carriers, individuals with GG genotype tended to be sensitive to platinum-based chemotherapy $(\mathrm{OR}=0.362$, $95 \% \mathrm{CI}=0.140-0.935, \quad p=0.036)$. However, no statistically significant differences were found between other SNPs and chemotherapeutic response (Supplement Table 1).

Table 4. Association between SNP and chemotherapeutic response in 158 NSCLC patients treated with platinum-based chemotherapy.

\begin{tabular}{|c|c|c|c|c|c|c|c|c|c|}
\hline \multirow[t]{2}{*}{ SNP } & \multirow[t]{2}{*}{ Genotype } & \multicolumn{2}{|c|}{ No. patients (\%) } & \multicolumn{2}{|l|}{ Additive } & \multicolumn{2}{|l|}{ Dominant } & \multicolumn{2}{|l|}{ Recessive } \\
\hline & & $\mathrm{CR}+\mathrm{PR}$ & SD+PD & OR(95\%CI) & $p$ & OR(95\%CI) & $p$ & OR(95\%CI) & $p$ \\
\hline \multirow[t]{3}{*}{ rs9526814 } & TT & $26(41.9)$ & $39(45.3)$ & 0.711 & 0.155 & 0.841 & 0.613 & 0.362 & 0.036 \\
\hline & TG & $22(35.5)$ & $38(44.2)$ & $(0.444-1.138)$ & & $(0.430-1.645)$ & & $(0.140-0.935)$ & \\
\hline & GG & $14(22.6)$ & $9(10.5)$ & & & & & & \\
\hline
\end{tabular}

CR: complete response; PR: partial response; SD: stable disease; PD: progressing disease; SNP: single nucleotide polymorphism; OR: odd ratio; CI: confidence interval. 


\section{Association between SNPs and ATP7B expression level}

Further, we aimed to explore whether the ATP7B SNPs had any regulatory effect on the expression level of ATP7B in NSCLC tissues. Additional 89 NSCLC patients were enrolled in the study. The clinical characteristics of the 89 patients were summarized in Table 5. No significant association was observed between ATP7B expression and age, sex, clinical stage, histological type and differentiation. We further assessed the expression of ATP7B in 247 NSCLC tissues with SNP genotype data. Results showed that rs9526814 was significantly associated with the expression level of ATP7B. In the presence of rs9526814 TT+TG genotypes, ATP7B levels in NSCLC tissues were markedly increased than those with GG genotype $(p=0.048)$ (Table 6). We performed a bioinformatics analysis, and found that rs9526814 has been predicted to be transcription factor binding site. The ATP7B rs9526814 may lead to variation of its gene expression levels to drive platinum resistance. No significant association was observed between other SNPs and ATP7B protein expression (Supplement Table 2).

Table 5. Clinicopathological characteristics with ATP7B protein expression in 89 NSCLC patients who underwent surgical resection.

\begin{tabular}{lllll}
\hline Characteristics & All patients & $\begin{array}{l}\text { ATP7B (+) } \\
\mathbf{n}(\%)\end{array}$ & $\begin{array}{l}\text { ATP7B (-) } \\
\mathbf{n}(\%)\end{array}$ & $p$ value \\
\hline $\begin{array}{l}\text { All patients } \\
\text { Age }\end{array}$ & $89(100.0)$ & $38(42.7)$ & $51(57.3)$ & \\
$<60$ years & $57(64.0)$ & $24(63.2)$ & $33(64.7)$ & 0.880 \\
$\geqq 60$ years & $32(36.0)$ & $14(36.8)$ & $18(35.3)$ & \\
$\begin{array}{l}\text { Gender } \\
\text { Male }\end{array}$ & $45(50.6)$ & $21(55.3)$ & $24(47.1)$ & 0.444 \\
$\begin{array}{l}\text { Female } \\
\text { Histology }\end{array}$ & $44(49.4)$ & $17(44.7)$ & $27(52.9)$ & \\
$\begin{array}{l}\text { Adenocarcinoma } \\
\text { Squamous cell }\end{array}$ & $45(50.6)$ & $23(60.5)$ & $22(43.1)$ & 0.240 \\
carcinoma & $42(47.2)$ & $14(36.8)$ & $28(54.9)$ & \\
$\begin{array}{l}\text { Adenosquamous } \\
\text { Clinical stage }\end{array}$ & $2(2.2)$ & $1(2.7)$ & $1(2.0)$ & \\
$\begin{array}{l}\text { I-II } \\
\text { III-IV }\end{array}$ & $38(42.7)$ & $20(52.6)$ & $18(35.3)$ & 0.102 \\
$\begin{array}{l}\text { Differentiation } \\
\text { Poor }\end{array}$ & $51(57.3)$ & $18(47.4)$ & $33(64.7)$ & \\
$\begin{array}{l}\text { Moderate } \\
\text { Well }\end{array}$ & $30(33.7)$ & $14(36.8)$ & $16(31.4)$ & 0.712 \\
\hline
\end{tabular}

\section{Discussion}

In the current study, we investigated the interrelationships between $A T P 7 B$ SNPs and protein expression, and their association with chemotherapy response in NSCLC patients. We found that ATP7B expression was associated with treatment outcome of platinum-based chemotherapy in NSCLC patients. In addition, SNP rs9526814 GG genotype tended to decrease ATP7B expression levels and acted as a potential biomarker to predict the sensitivity of platinum-based chemotherapy in NSCLC patients.

Table 6. Significant correlation between SNP and ATP7B protein levels.

\begin{tabular}{lllllll}
\hline & rs9526814 & & & & \\
\cline { 2 - 7 } & GG (\%) & TG (\%) & TT (\%) & $p$ & TG/TT (\%) & $\boldsymbol{P}^{*}$ \\
\hline ATP7B(+) & $15(40.5)$ & $54(54.0)$ & $60(62.5)$ & 0.069 & $114(58.2)$ & $\mathbf{0 . 0 4 8}$ \\
ATP7B(-) & $22(59.5)$ & $46(46.0)$ & $36(37.5)$ & & $82(41.8)$ & \\
\hline${ }^{*}$ GG vs. TG/TT & & & & & &
\end{tabular}

Up to now, multiple mechanisms have been proposed for platinum resistance, mainly including decreased cellular drug accumulation, enhanced drug inactivation, and increased DNA repair ability. Among these, intracellular accumulation of platinum drugs is an important determinant for their cytotoxic activity [25]. Copper efflux transporter ATP7B not only controls the elimination of copper ion, but also for the platinum-based antitumor agents. Previous studies have revealed that high ATP7B expression conferred resistance to platinum drugs in cells, while ATP7B knockdown partially reversed the resistance [26-30]. Furthermore, significant association between ATP7B expression and the efficacy of platinum-based chemotherapy was observed in several cancers including ovarian, colorectal, endometrial, esophageal, and oral sqamous cell carcinoma [10-14]. However, the clinical significance of ATP7B in NSCLC is still controversial. Inoue et al. evaluated the relationship between ATP7B mRNA expression and cisplatin sensitivity in 21 NSCLC patients, and found that ATP7B mRNA levels in cisplatin-resistant tumors were significantly higher than those in cisplatin-sensitive group [17]. Nevertheless, Chen et al. reported that overexpression of ATP7B was not associated with chemotherapy response and overall survival in 54 stage III NSCLC patients receiving platinum-based chemotherapy [16]. In the current study, we showed that individuals with ATP7B-negative tumors had improved chemotherapeutic response, as well as better survival in 158 NSCLC patients. The inconsistency may stem from differences in patient population, sample sizes and treatment modalities. Although the mechanisms by which ATP7B contributes to platinum resistance are not well understood, several hypotheses have been proposed including binding or sequestration of platinum drugs and facilitating the efflux of platinum drugs [7].

SNPs, at a specific base position in the human genome, can alter gene expression and protein functions. Studies have suggested that SNPs can influence drug transport, metabolism and cellular response, and lead to individual variations in terms of the response and toxicity $[18,31]$. In spite of the wide 
investigations of ATP7B expression on platinum resistance, no $A T P 7 B$ genetic polymorphism was identified to be associated with the efficacy of platinum-based chemotherapy in NSCLC patients. In this study, we observed that patients carrying rs9526814 GG genotype showed more sensitive to platinum-based chemotherapy than those carrying TG+TT genotypes. Moreover, the expression of ATP7B in tissues carrying GG genotype was significantly lower than those with TG+TT genotypes. However, the molecular function of rs9526814 has never been reported. We performed a bioinformatics analysis using SNP function prediction software (https://snpinfo.niehs.nih.gov/snpinfo/snpfunc.htm 1), rs9526814 has been predicted to be transcription factor binding site. The rs9526814 $\mathrm{T}$ allele generates the potential binding sites for the MYB, CP2, BRCA and SZF11 transcription factors (TFs), while the G allele creates potential binding sites for EGR1 and PAX8 TFs (Figure 3). The SNP variation of rs9526814 may affect the affinity of TFs with $A T P 7 B$, which results in allele-specific gene expression.

$$
\begin{aligned}
& 5^{\prime} \text {-tgtacggggttgtgcacttctgtgaaactcgc-3' } \\
& \frac{\frac{\text { MYB }}{\frac{\text { CP2 }}{\text { BRCA }}}}{\text { SZF11 }} \\
& 5^{\prime} \text {-tgtacgggggtgtgcacttctgtgaaactcgc-3' } \\
& \text { PAX8 }
\end{aligned}
$$

Figure 3. The sequences of SNP rs $9526814 \mathrm{~T}$ allele and $\mathrm{G}$ allele were shown. The consensus sequences for transcription factor binding sites were indicated by lines with the name of the factors.

Our study has several limitations. Firstly, larger multi-ethnic and multicenter studies are needed in the future due to modest sample size and lack of external validation in current study. Secondly, platinum-resistance is multifaceted, so it will be more valuable if combined with ATP7B and other factors to predict the sensitivity of platinum drug. Thirdly, the exact mechanism by which the SNP regulates ATP7B protein levels requires experimental verification.

In conclusion, our study showed that ATP7B expression was associated with treatment outcome of platinum-based chemotherapy in NSCLC patients. Additionally, SNP rs9526814 might act as a potential biomarker to predict the sensitivity of platinum-based chemotherapy in NSCLC patients. Mechanically, rs9526814 GG genotype could significantly attenuate ATP7B expression level.

\section{Abbreviations}

NSCLC: non-small cell lung cancer; SNP: single nucleotide polymorphism; CR: complete response;
PR: partial response; SD: stable disease; PD: progressive disease; OS: overall survival; HR: hazard ratio; $\mathrm{CI}$ : confidence interval; OR: odd ratio; MAF: minor allele frequency; TFs: transcription factors.

\section{Supplementary Material}

Supplementary tables.

http://www.jcancer.org/v09p3532s1.pdf

\section{Acknowledgements}

This study was funded by the Hunan Provincial Natural Science Foundation of China Grant (2016JJ2152) and the Fundamental Research Funds for the Central Universities of Central South University (2017zzts863).

\section{Competing Interests}

The authors have declared that no competing interest exists.

\section{References}

1. Siegel RL, Miller KD, Jemal A. Cancer statistics, 2016. CA: a cancer journal for clinicians. 2016; 66: 7-30.

2. Schiller JH, Harrington D, Belani CP, Langer C, Sandler A, Krook J, et al. Comparison of four chemotherapy regimens for advanced non-small-cell lung cancer. The New England journal of medicine. 2002; 346: 92-8.

3. Fossella F, Pereira JR, von Pawel J, Pluzanska A, Gorbounova V, Kaukel E, et al. Randomized, multinational, phase III study of docetaxel plus platinum combinations versus vinorelbine plus cisplatin for advanced non-small-cell lung cancer: the TAX 326 study group. Journal of clinical oncology : official journal of the American Society of Clinical Oncology. 2003; 21: 3016-24.

4. Amable L. Cisplatin resistance and opportunities for precision medicine. Pharmacological research. 2016; 106: 27-36.

5. Kuo MT, Chen HH, Song IS, Savaraj N, Ishikawa T. The roles of copper transporters in cisplatin resistance. Cancer metastasis reviews. 2007; 26: 71-83.

6. Li ZH, Zheng R, Chen JT, Jia J, Qiu M. The role of copper transporter ATP7A in platinum-resistance of esophageal squamous cell cancer (ESCC). Journal of Cancer. 2016; 7: 2085-92.

7. Li YQ, Yin JY, Liu ZQ, Li XP. Copper efflux transporters ATP7A and ATP7B: Novel biomarkers for platinum drug resistance and targets for therapy. IUBMB life. 2018; 70: 183-91.

8. Zhu S, Shanbhag V, Wang Y, Lee J, Petris M. A Role for The ATP7A Copper Transporter in Tumorigenesis and Cisplatin Resistance. Journal of Cancer. 2017; 8: 1952-8.

9. Nakayama K, Kanzaki A, Ogawa K, Miyazaki K, Neamati N, Takebayashi Y. Copper-transporting P-type adenosine triphosphatase (ATP7B) as a cisplatin based chemoresistance marker in ovarian carcinoma: comparative analysis with expression of MDR1, MRP1, MRP2, LRP and BCRP. International journal of cancer. 2002; 101: 488-95.

10. Nakayama K, Kanzaki A, Terada K, Mutoh M, Ogawa K, Sugiyama T, et al. Prognostic value of the $\mathrm{Cu}$-transporting ATPase in ovarian carcinoma patients receiving cisplatin-based chemotherapy. Clinical cancer research : an official journal of the American Association for Cancer Research. 2004; 10: 2804-11.

11. Martinez-Balibrea E, Martinez-Cardus A, Musulen E, Gines A, Manzano JL, Aranda E, et al. Increased levels of copper efflux transporter ATP7B are associated with poor outcome in colorectal cancer patients receiving oxaliplatin-based chemotherapy. International journal of cancer. 2009; 124: 2905-10.

12. Aida T, Takebayashi $Y$, Shimizu T, Okamura C, Higasimoto M, Kanzaki A, et al. Expression of copper-transporting P-type adenosine triphosphatase (ATP7B) as a prognostic factor in human endometrial carcinoma. Gynecologic oncology. 2005; 97: 41-5.

13. Miyashita H, Nitta Y, Mori S, Kanzaki A, Nakayama K, Terada K, et al. Expression of copper-transporting P-type adenosine triphosphatase (ATP7B) as a chemoresistance marker in human oral squamous cell carcinoma treated with cisplatin. Oral oncology. 2003; 39: 157-62.

14. Higashimoto M, Kanzaki A, Shimakawa T, Konno S, Naritaka Y, Nitta Y, et al. Expression of copper-transporting P-type adenosine triphosphatase in human esophageal carcinoma. International journal of molecular medicine. 2003; 11: 337-41.

15. Yang $\mathrm{T}, \mathrm{Chen} \mathrm{M}, \mathrm{Chen} \mathrm{T}$, Thakur A. Expression of the copper transporters hCtr1, ATP7A and ATP7B is associated with the response to chemotherapy 
Journal of Cancer 2018, Vol. 9

3539

and survival time in patients with resected non-small cell lung cancer. Oncology letters. 2015; 10: 2584-90.

16. Chen HH, Man JJ, Chen WC, Ko MT, La YH, La WW, et al. Predictive and prognostic value of human copper transporter $1(\mathrm{hCtr} 1)$ in patients with stage III non-small-cell lung cancer receiving first-line platinum-based doublet chemotherapy. Lung cancer (Amsterdam, Netherlands). 2012; 75: 228-34.

17. Inoue $\mathrm{Y}$, Matsumoto H, Yamada S, Kawai K, Suemizu H, Gina M, et al. ATP7B expression is associated with in vito sensitivity to cisplatin in non-small cell lung cancer. Oncology letters. 2010; 1: 279-82.

18. Yin JY, Li X, Chou HH, Lu ZQ. Pharmacogenomics of platinum-based chemotherapy sensitivity in NSCLC: toward precision medicine. Pharmacogenomics. 2016; 17: 1365-78.

19. Chen J, Wang Z, Zou T, Gui J, Yin J, Zheng W, et al. Pharmacogenomics of platinum-based chemotherapy response in NSCLC: a genotyping study and a pooled analysis. Oncotarget. 2016; 7: 55741-56.

20. He YJ, Winham SJ, Hoskins JM, Glass S, Paul J, Brown R, et al. Carboplatin/taxane-induced gastrointestinal toxicity: a pharmacogenomics study on the SCOTROC1 trial. The pharmacogenomics journal. 2016; 16: 243-8.

21. Li YQ, Zhang XY, Chen J, Yin JY, Li XP. ATP7B rs9535826 is associated with gastrointestinal toxicity of platinum-based chemotherapy in nonsmall cell lung cancer patients. Journal of cancer research and therapeutics. 2018; 14: $881-6$

22. Gong WJ, Yin JY, Li XP, Fang C, Ciao D, Zhang W, et al. Association of well-characterized lung cancer lncRNA polymorphisms with lung cancer susceptibility and platinum-based chemotherapy response. Tumour biology : the journal of the International Society for Oncodevelopmental Biology and Medicine. 2016; 37: 8349-58.

23. Therese P, Arbuck SG, Eisenhauer EA, Wanders J, Kaplan RS, Rubinstein L, et al. New guidelines to evaluate the response to treatment in solid tumors. European Organization for Research and Treatment of Cancer, National Cancer Institute of the United States, National Cancer Institute of Canada. Journal of the National Cancer Institute. 2000; 92: 205-16.

24. Li Q, Qu F, Li R, He X, Zhai Y, Chen W, et al. A functional polymorphism of SSBP1 gene predicts prognosis and response to chemotherapy in resected gastric cancer patients. Oncotarget. 2017; 8: 110861-76.

25. Hall MD, Okabe M, Shen DW, Liang XJ, Gottesman MM. The role of cellular accumulation in determining sensitivity to platinum-based chemotherapy. Annual review of pharmacology and toxicology. 2008; 48: 495-535.

26. Nakayama K, Miyazaki K, Kanzaki A, Fukumoto M, Takebayashi Y. Expression and cisplatin sensitivity of copper-transporting P-type adenosine triphosphatase (ATP7B) in human solid carcinoma cell lines. Oncology reports. 2001; 8: 1285-7.

27. Katano K, Safaei R, Samimi G, Holzer A, Rochdi M, Howell SB. The copper export pump ATP7B modulates the cellular pharmacology of carboplatin in ovarian carcinoma cells. Molecular pharmacology. 2003; 64: 466-73.

28. Xu W, Cai B, Chen JL, Li LX, Chang JR, Sun YY, et al. ATP7B antisense oligodeoxynucleotides increase the cisplatin sensitivity of human ovarian cancer cell line SKOV3ipl. International journal of gynecological cancer : official journal of the International Gynecological Cancer Society. 2008; 18: 718-22.

29. Mandala LS, Zuzel V, Schmandt R, Leshane ES, Holder JB, Armaiz-Pena GN, et al. Therapeutic Targeting of ATP7B in Ovarian Carcinoma. Clinical cancer research: an official journal of the American Association for Cancer Research. 2009; 15: 3770-80.

30. Yoshizawa K, Nozaki S, Kitahara H, Ohara T, Kate K, Kawashiri S, et al. Copper efflux transporter (ATP7B) contributes to the acquisition of cisplatin-resistance in human oral squamous cell lines. Oncology reports. 2007; 18: $987-91$.

31. Telling MV, Evans WE. Pharmacogenomics in the clinic. Nature. 2015; 526: 343-50.

http://www.jcancer.org 